\title{
Repetition Preferences in Two-Handed Balanced Signs: Vestigial Locomotor Central Pattern Generators Shape Sign Language Phonetics and Phonology
}

OPEN ACCESS

Edited by:

Ping Li,

Hong Kong Polytechnic University,

Hong Kong

Reviewed by:

Marilyn Vihman,

University of York, United Kingdom

Bencie Woll,

University College London, United Kingdom

*Correspondence:

Oksana Tkachman

o.tkachman@alumni.ubc.ca

Specialty section: This article was submitted to

Language Sciences,

a section of the journal

Frontiers in Communication

Received: 01 October 2020 Accepted: 31 December 2020

Published: 28 January 2021

Citation:

Tkachman O, Purnomo G and Gick B (2021) Repetition Preferences in Two-

Handed Balanced Signs: Vestigial Locomotor Central Pattern Generators

Shape Sign Language Phonetics

and Phonology.

Front. Commun. 5:612973.

do: $10.3389 /$ fcomm.2020.612973

\author{
Oksana Tkachman ${ }^{1 *}$, Gracellia Purnomo ${ }^{1}$ and Bryan Gick ${ }^{1,2}$ \\ ${ }^{1}$ University of British Columbia, Vancouver, Canada, ${ }^{2}$ Haskins Laboratories, New Haven, CT, United States
}

Language is produced by bodies that evolved to fulfill a variety of functions, most of them non-communicative. Vestigial influences of adaptation for quadrupedal locomotion are still affecting bimanual actions, and have consequences on manual communication systems such as sign languages of the deaf. We discuss how central pattern generators (CPGs), networks of nerve cells in the spinal cord that drive locomotion, influence bimanual actions with alternating movements to be produced with repeated motion. We demonstrate this influence with data from three unrelated sign languages, American Sign Language, British Sign Language, and Hong Kong Sign Language: in all three sign languages two-handed balanced signs produced with alternating movements have a tendency to be repeated, whereas other types of two-handed balanced signs show the opposite tendency for single movements. These tendencies cannot be fully explained by factors such as iconicity. We propose a motoric account for these results: as alternating bimanual movements are influenced by locomotor patterns, they favor repeated movements.

Keywords: sign language, central pattern generators (CPGs), bimanual movement, sign language phonetics, sign language phonology

\section{INTRODUCTION}

Language is produced by the body, which means that in language emergence the body must play a crucial role by favoring signals that are easy to articulate (Stavness et al., 2012). However, the body has many other, non-communicative functions, and has evolved to fulfill these functions. As nature is a great tinkerer (Jacob, 1977), the body often employs older adaptations to fulfill new duties. For example, birds' feathers first evolved for temperature regulation, but later became adapted for flight (Gould and Vrba, 1982). In this paper, we argue that some properties of sign languages can be explained by such adaptations, and we draw parallels with spoken languages. Specifically, we focus on central pattern generators (CPGs), which are networks of nerve cells located in the spinal cord often associated with control of repetitive or cyclic motion, such as locomotion (Grillner, 1985; Grillner and Wallen, 1985). CPGs have been suggested to play a role in speech (MacNeilage, 1998). In this paper, we will show how CPGs affect two-handed balanced signs in sign languages.

CPGs evolved for quadrupedal locomotion long before human ancestors became bipedal, and, even though humans are now bipedal, CPGs still operate in human arms. They can be seen, for example, in the coordination of arms and legs in activities such as walking, running, and swimming 
(van Emmeriket al., 1998). Arm swing, for instance, exists because of the vestigial quadrupedal CPGs still operating in the arms (Dietz, 2002; Meyns et al., 2013), and the activation of CPGs is similar in arms and legs during walking (Zehr and Duysens, 2004). This pattern of out-of-phase movement of arms and legs (that is, the pattern where a front limb and a hind limb diagonal to it move together) is still beneficial for walking, as it helps humans walk in a more stable manner and spend less energy on movement (Meyns et al., 2013). We do not see such movement patterns in bipedal species that did not evolve from quadrupedal ancestors. Birds are one such example: they descended from a group of bipedal dinosaurs, and developed flight long after they became bipedal. Walking and flying in birds are controlled by independent musculoskeletal systems, and wing and tail muscles are inactive during walking (Ostrom, 1986; Butler, 1991; Gatesy and Dial, 1996). Even in aquatic birds, both those that developed the ability to swim and dive in addition to the ability to fly and those that abandoned flight altogether, leg and wing muscles are never activated together: there are either wing-propellers (penguins, auklets) or footpropellers (Galapagos cormorant, loons), but no wing-and-foot propellers (Gatesy and Dial, 1996). There is no "wing swing" in birds, because they have never been quadrupedal. In humans, who are comparatively recent descendants from quadrupedal species, the vestigial CPGs still generate rhythmic movement patterns in arms. Therefore, we can expect these CPGs to affect other manual activities, such as the conventionalized manual movement systems used in natural sign languages of the deaf.

Sign languages are fully-fledged languages with all levels of linguistic organization (Sandler and Lillo-Martin, 2006), they emerge whenever there is a community of deaf people (Sandler and Lillo-Martin, 2006; Meir et al., 2010). They are acquired naturally by infants in similar ways and following similar milestones as infants acquiring spoken languages (Chen Pichler, 2012). Since sign languages are visual-manual, the hands are the (most) active articulators, with the dominant hand being active in all signs and the nondominant hand in some signs. There are therefore three types of signs, one-handed (produced just by the dominant hand), two-handed unbalanced (where the nondominant hand acts as a passive place of articulation for the dominant hand, often with the nondominant hand having a different, more basic handshape from that of the dominant hand) and two-handed balanced (where both hands have the same handshape and move in a similar fashion) (Battison, 1974). In spoken languages, many linguistic generalizations are explained (or hypothesized as being explained) by reference to articulatory ease (Ladefoged, 1984; Lindblom, 1990, Lindblom, 1998; Stavness et al., 2012). In signed languages, therefore, one would expect two-handed balanced signs to be rare, since moving two hands actively doubles articulatory effort and requires the biggest reactive effort to stabilize the torso (Sanders and Napoli, 2016), but in actuality they are very frequent (e.g., one-third of the entire lexicon of American Sign Language, Klima and Bellugi, 1979). They are known to resist change, either in phonological or historical processes, and are preferred in both first and second language acquisition (Cheek et al., 2001; Chen Pichler et al., 2016).
Moreover, some unbalanced signs become balanced over time (Frishberg, 1975; Padden and Perlmutter, 1987).

Not only are balanced signs widespread and resistant to change compared to other types of signs, but within the group of balanced signs, signs produced with alternating movements (as in locomotion) show more resistance to change than signs produced with symmetrical movements. Some phonological rules do not apply to two-handed signs with alternating movement: e.g., under certain circumstances it is possible to drop the nondominant hand from a two-handed sign (weak drop); however, if the sign has an alternating movement, such weak drop is prohibited (Battison, 1974; Padden and Perlmutter, 1987; Brentari 1998), especially if the alternating movement in the sign is iconic (in the Sign Language of the Netherlands, see van der Kooij et al. 2001) (What we describe here is only true for weak drop in balanced signs, the focus of the present study. However, the phenomenon of weak drop in unbalanced signs is much more complicated, especially in the case of iconic signs. The interested reader is referred to Vennes (2018) for a recent review on weak drop and the related phenomenon of weak hand lowering). The same resistance to weak drop is observed in first-language acquisition (Siedlecki and Bonvillian, 1993). And the many linguistic processes that turn one-handed signs into two-handed signs result in signs with alternating, not symmetrical movements (Padden and Perlmutter, 1987).

We hypothesize that these properties of balanced signs can be explained by the effect of cyclic CPGs. If two-handed balanced signs are indeed influenced by vestigial locomotive CPGs, which govern repetitive cyclic movements, we should expect that in signs where the two hands actively move in an alternating manner (as in locomotion), the movement of the signs should favor repetition, whereas in signs where hands move in a non-alternating manner (i.e., symmetrically), the movement should show no such preference. To test this prediction, we examine data from three genetically unrelated sign languages: American Sign Language (ASL), British Sign Language (BSL), and Hong Kong Sign Language (HKSL) (ASL belongs to the French Sign Language family, BSL to the British Sign Language family, and HKSL to the Chinese Sign Language family (Wittmann, 1991)). We also discuss some other potential influences on the form of signs, such as iconicity. We end by proposing a neuromotor account for the movement properties we see in balanced signs.

\section{MATERIALS AND METHODS}

\section{Data}

To avoid any language-specific confounding factors, we coded dictionaries of three unrelated sign languages: American Sign Language (Costello et al., 1998), British Sign Language (Brennan and Brien, 1992) and Hong Kong Sign Language (Tang, 2007). All two-handed balanced signs listed in these dictionaries were coded and analyzed. Using dictionaries allowed us to collect data in an unbiased manner, as well as focus on more representative signs from the respective sign languages. 


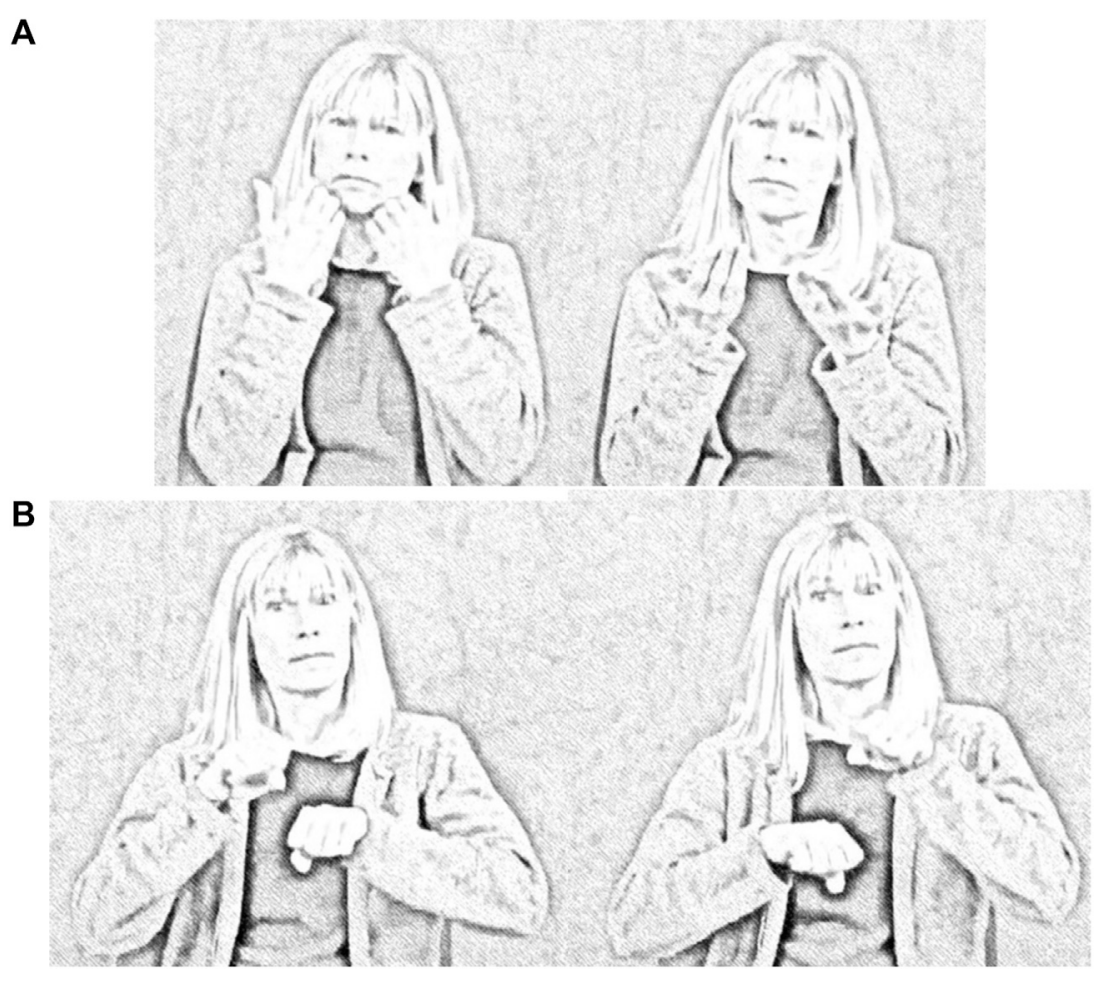

FIGURE 1 | Examples of two-handed balanced signs from ASL classified as symmetrical (A) or alternating (B). (A) SHAME, is produced with a single movement of both hands moving away from the signer's body; (B) BICYCLE, is produced with two hands moving in a repeated alternating cyclic motion (We follow the field's convention of glossing signs with small caps). Examples are from the online dictionary ASL-Lex (Caselli et al. 2017).

\section{Annotation}

All signs in the three dictionaries were annotated by the second author, a hearing non-signer, as one-handed, two-handed unbalanced and two-handed balanced. The latter group of balanced signs was further annotated for movement pattern (symmetrical, alternating, other movement, or no movement), movement repetition (single/repeated), iconicity (whether the sign is iconic as judged by a sign-naïve hearing research assistant, yes/ no) ${ }^{1}$, and whether the sign is a compound (Table 1). Iconic signs were further annotated for whether or not they depicted a human activity that requires an alternating limb movement (regardless of which limbs are prototypically employed in this activity) (Two activities, skiing and rope-jumping, which could be performed with either alternating or symmetrical bimanual movements, were annotated as alternating-movement activities to avoid

'(Iconicity of signs is by no means an easily-identified and objective property (Occhino et al., 2017; see Motamedi et al., 2019 for many different approaches to identifying iconicity in both signed and spoken languages). In this study, signs were coded as iconic if a sign-naïve coder who was not blind to the meaning of signs could see some motivation behind the signs' forms. In this way, we sought to escape possible influences of familiarity with a specific sign language (e.g., an actual or folk etymology of the signs that is no longer visible in the signs' forms, influences on form that are related to systematicity rather than iconicity (see Dingemanse et al., 2015), etc.), while also removing the guesswork that is often employed in judging signs as iconic or not (when only transparent signs whose meaning is easily guessed by sign-naïve hearing people are taken to be iconic). downplaying the potential role of iconicity). In addition, alternating signs were coded for which hand is higher at the beginning of the sign production or throughout the sign production. Here we will only report results relevant to this paper's research question.

Signs were classified as either symmetrical or alternating if they were produced with symmetrical or alternating movement but were not produced in the horizontal plane (see Figure 1). Some signs did not have major movement in their citation form, and thus were classified as no-movement signs (Such signs could include other types of movement, such as handshape-internal movement, when the hand does not move in space but the handshape changes, or transitional movement, where the hand moves to a place of sign's articulation. We did not code for these types of movement). Signs classified as "other" employed movement in a manner not compatible with any locomotive pattern (e.g., both hands moving from side to side in the same direction, see Figure 2), and thus not suitable for testing of our prediction.

\section{RESULTS}

\section{Overall Results}

The ASL dictionary had 4217 entries, of which 1407 (33\%) were two-handed balanced signs or compounds containing at least one two-handed balanced sign. 160 of these entries were identified as 


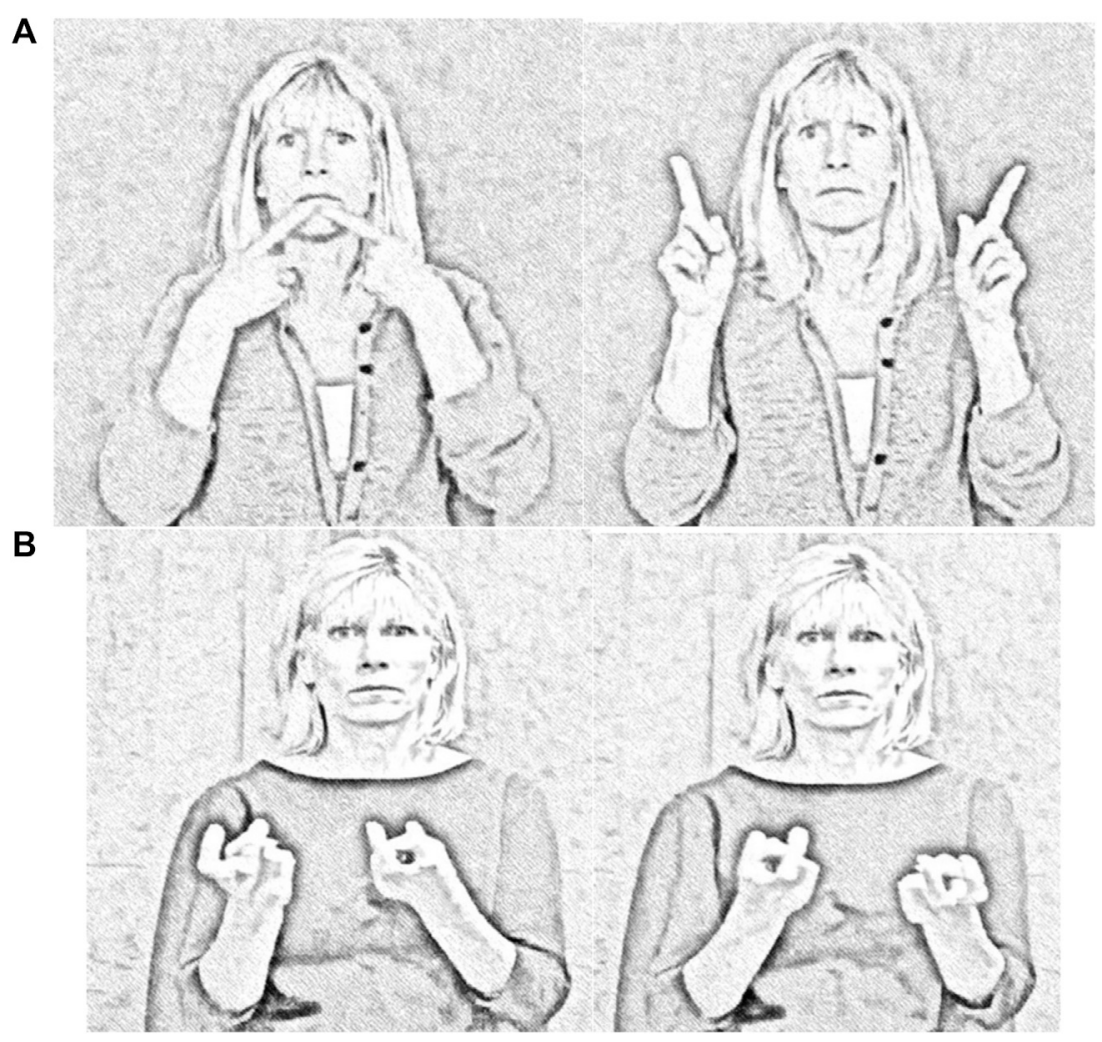

FIGURE 2 | ASL signs moving on the horizontal plane either in the opposite directions ((A), ANNOUNCE) or in the same direction ((B)), ROLLER-SKATING). EXamples are from the online dictionary ASL-Lex (Caselli et al. 2017).

TABLE 1 | Annotation parameters for two-handed balanced signs.

\section{Annotation parameter}

Movement pattern

Movement repetition Iconicity alternating-limbmovement activity

Compound

compounds and excluded from the analysis, leaving 1247 signs. The BSL dictionary consisted of 1367 entries, of which 421 (31\%) were two-handed balanced. After excluding 29 compounds, the final BSL dataset consisted of 394 signs. The HKSL dictionary consisted of 1864 entries, of which 498 (27\%) were two-handed balanced. Excluding 65 compounds, the final dataset consisted of 433 signs.

\section{Alternating and Symmetrical Signs}

There were 211 alternating and 355 symmetrical ASL signs, 70 alternating and 112 symmetrical BSL signs, and 64 alternating and 84 symmetrical HKSL signs. As predicted, alternating signs tended to be repeated: $73 \%$ of ASL alternating signs, $81 \%$ of BSL alternating signs, and $65 \%$ of HKSL alternating signs had movement repetition in their citation form Table 2 . Also as predicted, symmetrical signs tended to have a single movement in their citation form: $77 \%$ of ASL symmetrical signs, $73.5 \%$ of BSL symmetrical signs, and $64 \%$ of HKSL symmetrical signs (see Figure 3). These results were significant: ASL: $\chi^{2}(1)=128.622, p<0.001$, BSL: $\chi^{2}(1)=51.548$, $p<0.001$, HKSL: $\chi^{2}(1)=11.557, p<0.001$.

For the purpose of comparison, we also looked at repetition patterns in other balanced signs, signs that did employ movement but mostly in the horizontal plane in a manner not compatible with locomotive patterns and thus outside of our prediction (see Figure 2). In all three sign languages, these signs tended not to be repeated: only $22 \%(114 / 515)$ were repeated in ASL, 31\% (53/170) in BSL and $32 \%(58 / 182)$ in HKSL.

In all three sign languages, alternating signs tended to either start with the dominant hand above the nondominant hand, or to be articulated with the dominant hand in the higher position throughout the sign production: $60 \%$ in ASL, $56 \%$ in BSL, and $45 \%$ in HKSL. In addition, $19 \%$ of ASL alternating signs, $14 \%$ of BSL signs, and $20 \%$ of HKSL were articulated with both hands at the same height.

\section{Iconic Signs}

Iconicity was widespread across all subtypes of balanced signs: the lowest percentage of iconic signs was $30 \%$ and the largest was $50 \%$ per type of balanced signs. In ASL, 35\% of alternating signs were classified as iconic, compared to $50 \%$ in BSL and $30 \%$ in HKSL; and $35 \%$ of ASL symmetrical signs were classified as iconic, compared to $44 \%$ of BSL and $44 \%$ of HKSL symmetrical signs (see Table 3 for raw numbers). The distribution of iconic signs in 


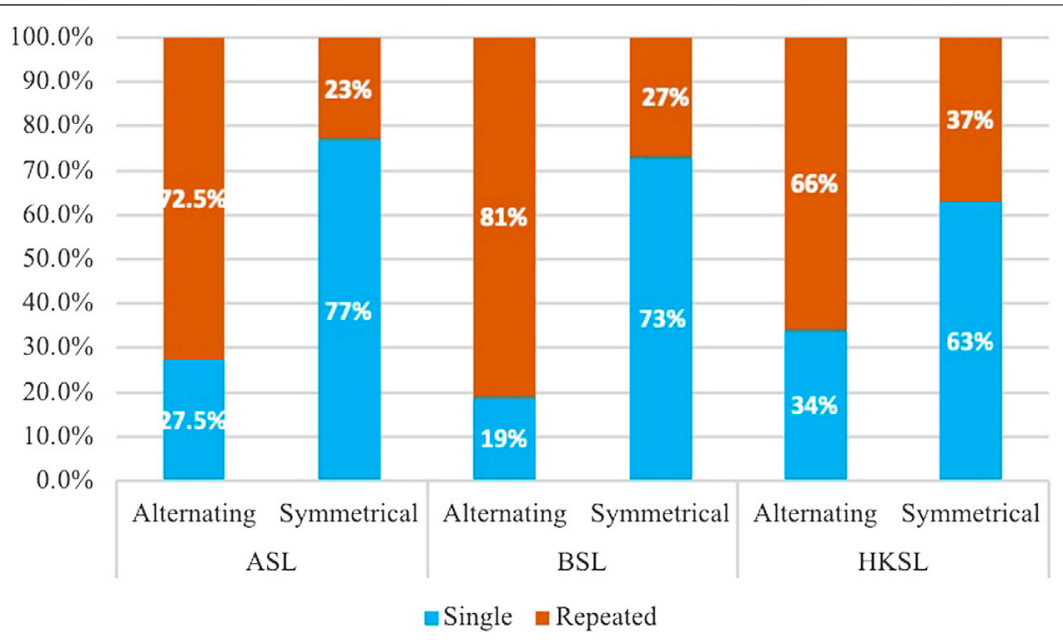

FIGURE 3 | The distribution of repeated and single movements in alternating and symmetrical signs in three sign languages (in percentages).

TABLE 2 | Number of repeated tokens for alternating and symmetrical signs in the three sign languages.

\begin{tabular}{lcc} 
& Alternating & Symmetrical \\
\hline ASL & $153 / 211$ & $83 / 355$ \\
BSL & $57 / 70$ & $30 / 112$ \\
HKSL & $42 / 64$ & $31 / 84$
\end{tabular}

TABLE 3 | Number of iconic tokens for alternating and symmetrical signs in the three sign languages.

\begin{tabular}{lcc} 
& Alternating & Symmetrical \\
\hline ASL & $73 / 211$ & $124 / 355$ \\
$B S L$ & $35 / 70$ & $49 / 112$ \\
HKSL & $19 / 64$ & $37 / 84$
\end{tabular}

alternating and symmetrical signs was not significantly different between the three sign languages: $\chi^{2}(2)=3.703, p=0.157$. The distribution of iconic signs in alternating and symmetrical signs was not significantly different within individual sign languages either: in ASL, $\chi^{2}(1)=5.22, p=0.022$; in BSL, $\chi^{2}(1)=0.502, p=$ 0.479; in HKSL, $\chi^{2}(1)=4.8, p=0.028$.

Iconic signs did not differ in their preferences for repetition in BSL and HKSL: in BSL $83 \%$ of iconic alternating signs were repeated and $71 \%$ of iconic symmetrical signs were single, compared to 81 and $73.5 \%$ of all alternating and symmetrical signs, respectively $\left(\chi^{2}(1)=0.032, p=0.858\right.$ for alternating signs, $\chi^{2}(1)=0.055, p=0.814$ for symmetrical signs); similarly, in HKSL $63 \%$ of iconic alternating signs were repeated and $62 \%$ of iconic symmetrical signs were single, compared to 65 and $64 \%$ of all alternating and symmetrical signs, respectively $\left(\chi^{2}(1)=0.039\right.$, $p=0.843$ for alternating signs, $\chi^{2}(1)=0.003, p=0.956$ for symmetrical signs). In ASL, both iconic alternating signs and iconic symmetrical signs displayed even stronger movement preferences, for repetition in alternating signs ( $78 \%$ compared to $73 \%$ of all alternating signs) and for single movement in symmetrical signs ( $84 \%$ compared to $77 \%$ of all symmetrical signs), though this difference was not statistically significant (for alternating signs: $\chi^{2}(1)=0.873, p=0.35$; for symmetrical signs: $\chi^{2}$ $(1)=0.029, p=0.865)$, nor was it significant if compared only to non-iconic signs $\left(\chi^{2}(1)=1.738, p=0.187\right.$ for alternating signs, $\chi^{2}$ (1) $=0.06, p=0.806$ for symmetrical signs).

The percentage of iconic signs representing alternating limb movement in alternating signs was relatively low: the highest was in BSL, where $28.5 \%$ of alternating iconic signs depicted such activities, compared to $25 \%$ in ASL and $16 \%$ in HKSL. Not surprisingly, symmetrical signs tended not to depict such activities: only two of symmetrical iconic signs in ASL, two in BSL and three in HKSL did so. Interestingly, iconic signs depicting activities typically performed with alternating bimanual movements did not differ in their preferences for repeated motion from other iconic signs: in ASL, both types of iconic signs employed repeated motion in $78 \%$ of cases (no statistically significant difference, $\chi^{2}(1)$ $=0, p=1$ ); in BSL, $90 \%$ of the former and $75 \%$ of the latter were repeated (no statistically significant difference, $\chi^{2}(1)=0.503, p=$ 0.478). In HKSL, signs not depicting bimanual alternating activities were repeated in $56 \%$ of cases, and the only three signs that did depict such activities were all repeated; however, the number of tokens was very low in HKSL (16 and 3), and no statistical difference between the two was found $\left(\chi^{2}(1)=2.078, p=0.149\right)$.

\section{DISCUSSION}

Languages, spoken and signed, are produced by human bodies and constrained by biomechanics. Though particular biomechanical adaptations may be modality-specific (Ostry et al., 1987; Grosvald and Corina, 2012), the principles are modality-general: languages exploit what is possible and easy to articulate, and what is already available. That is, if specific motor behavior already exists for non-linguistic purposes, but can be exploited for linguistic purposes, it probably will be (MacNeilage, 1998). In this paper, we tested the proposal that otherwise unexplained universal aspects of sign languages (the privileged position of alternating balanced signs in acquisition 
and language change) can be understood as resulting from a preference for repeated alternating arm movements triggered by vestigial locomotor CPGs developed in human ancestors for quadrupedal locomotion. There may be many motoric reasons for moving both hands simultaneously in signing: it can increase perceptibility of the sign (because it is easier to notice two moving objects rather than just one, Bruce and Green, 1990), it may be easier in motor planning (by executing one motor plan for two limbs, rather than for each limb individually, see Kelso et al., 1979), etc. However, moving two hands in repeated motions rather than in a single motion increases articulatory effort, especially when two hands are moving. Thus, the existence of alternating two-handed signs is more puzzling than the existence of two-handed signs employing other movement patterns.

In this study, we showed that even in genetically-unrelated sign languages, two-handed balanced signs tend to be articulated with a single motion, unless their movement is alternating. In signs with alternating movement, the repeated motion pattern is preferred instead. We attribute this pattern to central pattern generators (CPGs), that originally evolved for quadrupedal locomotion but still exert their influence on bimanual actions (van Emmerik et al., 1998) and are activated in arm swing during walking, even when the arms are constrained (Ballesteros et al., 1965; Kuhtz-Buschbeck and Jing, 2012). If CPGs affect manual actions, it is natural to expect them to exert some influence on sign languages, which are produced and perceived in the visualmanual modality. As we noted above, languages exploit what is easy to articulate by the body, and if repeated alternating bimanual movements are exploiting vestigial locomotive CPGs, their influence should be seen at least to some extent in sign languages as well. Indeed, there appears to be much evidence to support this expectation.

First, infants in general have difficulty with moving only one hand, preferring to use both hands, whether for linguistic or nonlinguistic purposes (Cheek et al., 2001). And infants acquiring sign languages natively strongly prefer two-handed signs that are balanced and repeated. They have a harder time acquiring onehanded signs, and often are less accurate in producing handshapes of one-handed signs even if they can produce exactly the same handshapes in two-handed signs (Siedlecki and Bonvillian, 1993). Not only one-handed signs, but also two-handed unbalanced signs (where the nondominant hand is a passive place of articulation for the dominant hand) are underrepresented in early signs as compared to their frequency in ASL (one study found less than $10 \%$ of unbalanced signs in their corpus of early child signing, Cheek et al., 2001), and unbalanced signs start to emerge only in late infancy (Fagard, 1994). Not only do infants prefer to move both hands simultaneously, but they also prefer signs with repeated movements, and acquire them more accurately; moreover, they tend to produce singlemovement signs with multiple movements most of the time (50-80\%; Meier et al., 1998; Holzrichter and Meier, 2000; Meier et al., 2002; Meier, Mauk et al., 2008; see also Juncos et al., 1997, Morgan et al., 2007). It appears that in first language acquisition, signing infants rely on CPGs in acquiring signs with two-handed repeated movements, whether the sign calls for them or not. And this may be true of adults as well: hearing adult second-language learners also tend to produce signs with multiple repetitions (Chen Pichler et al., 2016). The same tendency also surfaces in signers affected by disease: in one study, a signer affected by infarct substituted one-handed signs with two-handed balanced signs, with identical handshape and movement in both hands (Hickok et al., 1996). Abnormal sign repetition (palilalia) can also occur in signers suffering from progressive supranuclear palsy (Tyrone and Woll, 2008). Inhibition of movement, therefore, requires effort, suggesting that one-handed signs or signs with single movement are not necessarily easier to articulate simply because they are produced with less movement.

Second, two-handed alternating signs resist phonological and coarticulatory change. For example, sometimes two-handed signs can be realized phonetically with the dominant hand only in the process called weak drop (Padden and Perlmutter, 1987). However, if the two-handed sign has an alternating movement, weak drop is prohibited (see Battison, 1974; Brentari, 1998 for ASL, van der Kooij et al., 2001 for the Sign Language of the Netherlands). And such signs resist weak drop not only in adult signers, but also in children acquiring sign language natively (Siedlecki and Bonvillian, 1993), suggesting that the reason for this resistance is indeed motoric and not language-internal (though iconicity may prevent weak drop as well, in cases where the alternating movement is motivated by the sign's semantics, van der Kooij et al., 2001). And in the processes that turn one-handed signs into two-handed signs, the output is two-handed signs with alternating movements (e.g., in the Characteristic Adjective derivation, where a sign meaning " $\mathrm{X}$ " turns into a sign with the meaning characteristically "X," Padden and Perlmutter, 1987).

If two-handed signs with repeated alternating movements are indeed so easy to produce, then why don't sign lexicons predominantly consist of such signs? This, we believe, is due to the fact that sign lexicons are under multiple conflicting pressures, from both the production and the perception sides of communication, each selecting for different type of signs. For example, signs moving on the horizontal plane (that we discussed as "other" balanced signs in the results section) may be selected for because they are more visible to the addressee (see Tkachman et al., 2019 for discussion). Two-handed balanced signs with symmetrical movements may be easier to produce because they are exploiting a single motor plan and thus do not involve as much computational cost (Kelso et al., 1979). And, of course, onehanded signs only require moving one arm, which reduces the overall articulatory effort (Napoli et al., 2014). Thus, the preference for repeated alternating bimanual movements is only one easy biomechanical adaptation available to signers, among many others.

Other factors may also affect the form of signs. Cultural practices are one such example. For example, in Ghana there exists a strong taboo against pointing with one's left hand, which sometimes results in people pointing with both hands simultaneously, which does not violate this taboo (Kita and Essegbey, 2001). Though we are not aware of studies describing such influences behind handedness in sign languages, it is nevertheless possible that in some signs the number of hands or their movement is selected under some kind of cultural pressure. Another undisputed factor is linguistic; 
sign-language grammars often employ repeated motions to mark grammatical features. For example, some sign languages employ repeated movements for nominal signs and single movements for verbal signs in noun-verb pairs with otherwise similar forms and related meanings, such as "a hammer" and "to hammer" (see Supalla and Newport, 1978 for ASL, Johnston, 2001 for Australian Sign Language, Tkachman and Sandler, 2013 for Israeli Sign Language). Thus, the distribution of formational features is also subject to grammar, and frequencies of some of them may be affected by what is grammaticalized in an individual sign language. This last point is also relevant for another potential confounding issue: frequency of formational features in sign types is not necessarily revealing of their frequencies in sign tokens. For example, Crasborn and Safar (2016) show that in the Sign Language of the Netherlands, the frequencies of one-handed sign types in dictionaries is just over half of all types, but in a corpus of spontaneous signing $67.7 \%$ of all tokens are one-handed. Some of the preferences discussed in this paper may not be as frequent in spontaneous signing as they are in sign types. Nevertheless, the fact that these tendencies are evident in lexical signs that were coined and conventionalized does suggest that these motoric pressures are at work at some level, at least in language emergence and development. This possibility appears plausible especially in light of research on historical change: in ASL, some one-handed signs produced below the neck became two-handed, and some unbalanced signs became balanced (Frishberg, 1975).

Another possible influence is iconicity, or resemblance between the form of the sign and its meaning (Taub, 2001). For example, in iconic signs, the number of articulators may represent the number of referents, and the movement of hands may represent the movement of hands in some action, such as signing (Taub, 2001). One study on iconic motivation in twohanded signs of three unrelated sign languages (ASL, Swedish and Israeli Sign Languages) identified a number of semantic patterns related to different types of plurality, such as interaction between different entities (e.g., "meet"), location (e.g., "empty"), dimensions of one entity (e.g., "large"), and composition of one entity (e.g., "machine," Lepic et al., 2016). This tendency of selecting for two-handedness in signs for meanings related to plurality may be related to the metaphorical extension "more of form is more of content" (Lakoff and Johnson, 1980). This possibility is supported by a large cross-linguistic corpus study by Östling et al. (2018), who rated entries for 31 sign languages in the online dictionary Spread the Sign for signs' perceived plurality. They found that core vocabulary (signs representing the version of the Swadesh list adapted for sign languages) has almost equal distribution of two-handed signs (56\%), whereas the extended vocabulary (all non-compound signs) shows a much higher tendency for two-handed signs, $71 \%$. Using the list of 81 lexical plurals, Östling et al. (2018) found that lexical plurality is a strong factor behind two-handedness, but other concept-specific properties are also important in determining whether the sign is one- or two-handed. Repetition of movement may also be motivated by iconicity. In ASL, verbal signs that denote actions requiring duration or reiteration may employ repeated movement in their lexical forms (Supalla and Newport, 1978).
Moreover, Wilbur (2008) argues that movement in many verbs, adverbs and adjectives indicates the temporal extent of the event they denote, and movement repetition in lexical forms may be related to telicity.

Thus, meaning is one of the factors selecting for twohandedness and repeated movement in signs, and can in principle select for repeated alternating and single symmetrical movements as well. However, in our dataset, signs identified as iconic were not significantly different in their movement preferences from non-iconic signs. This finding can have different interpretations. It may be the case that in iconic signs, iconicity determines movement patterns, whereas in non-iconic signs, motoric preferences are selected for instead. This possibility, however, cannot explain why the proportion of single and repeated signs was so similar in iconic and non-iconic signs. Another possibility is that even in iconic signs, motor preferences are still strong and will be selected for. This possibility would be more in line with our findings, and the fact that iconic signs in ASL showed an even more pronounced tendency for repeated movement in alternating signs and single movement in symmetrical signs could be due to the combined effect of CPG influence and iconic choice for a semantically motivated form. Whatever may be the case, iconicity alone cannot account for our findings. Iconicity also cannot account for acquisition preferences in signing infants, because young children are not sensitive to iconicity (Tolar et al., 2008; Meier et al., 2008, though see Thompson et al., 2012; Perniss et al., 2018).

The final factor we address is that of perception. It may be that repeated movement is employed in alternating signs to increase their perceptibility, since presumably the more the hands move the easier it is to notice them. In fact, there are two aspects of these signs that potentially make them easier to perceive: more movement is easier to perceive than less movement and two-handed signs are easier to perceive than one-handed signs (because it is easier to notice two moving objects rather than just one, Bruce and Green, 1990). The first aspect appears to be supported by research on prominence in sign languages: many of the modifications that make a sign prominent involve an increase in movement. For example, stressed signs in ASL often involve more iterations of the movement (Wilbur and Nolen, 1986). Signs produced at prosodic boundaries often involve more duration, repetition and movement size (see Ormel and Crasborn, 2012 for an overview), and the same changes are involved in sign prominence (Nespor and Sandler, 1999) and sonority (Brentari, 1998). Similarly, the related phenomena of sign whispering (when the signer wants to conceal their signing from everyone but the chosen interlocutor) and sign shouting (when the signer addresses a larger group, such as in lecturing), the modifications are often to the size of the sign movements (reduced and lowered in whispering and enlarged and lifted in shouting) and to the number of hands used (one-handed versions of signs are preferred in whispering and two-handed in shouting, see Emmorey, 2001 for ASL and Crasborn, 2001 for the Sign Language of Netherlands). The handedness of the signs and their perceptibility are also discussed in a well-known proposal by Siple (1978), who suggested that, because signers look each other in the face during sign conversations, signs produced lower in the signing space are harder to perceive than signs produced higher in the 
signing space, and because of that signs lower in the signing space should favor two-handed forms (among other predictions not relevant here, see Siple, 1978 for details). One recent study tested this proposal by measuring the amount of visible movement in signs of one corpus of ASL (ASL-Lex, Caselli et al., 2017). Researchers showed that in this corpus, onehanded signs were indeed more likely to be signed higher in the signing space, and that two-handed signs were produced with more visible movement than one-handed signs (Tkachman et al., 2019). Thus, it is reasonable to suggest that alternating signs favor repeated motions for increased perceptibility. However, this suggestion does not explain why other types of balanced signs prefer single movements instead. This suggestion also does not explain the observation of Tkachman et al. (2019) that two-handed balanced signs tended to be articulated higher in the signing space than unbalanced signs, despite the fact that balanced signs generate more visible movement than unbalanced signs $(31 \%$ of balanced signs in the corpus were produced in locations higher than the neutral signing space, compared to only $10 \%$ of unbalanced signs). To us this suggests that perceptibility may not be the reason why alternating signs favor repeated motion, it is more likely that perceptibility is just one of the reasons why these signs resist change (which would lead to reduction in movement and therefore less perceptibility).

One potentially relevant piece of evidence for our claim can come from research on co-speech gesture in hearing people. Indeed, if bimanual movements have a motoric preference for alternation, this preference should be apparent not only in signs but also in gesture. However, gestures for the most part are not conventionalized, and therefore are subject to constraints of their immediate context of use. Some research on co-speech gestures (not conventionalized emblems) indicates that the bimanual behavior of iconic gestures depends largely on the content of the message (that is, both hands gesture when the content of the message calls for both hands), and that co-speech gesture in general tends to be unimanual (e.g., Lausberg and Kita, 2003). And of course, gestures are largely analogous and not made up of discrete contrastive units like signs, which makes direct comparisons of formational features difficult, even for moreor-less conventionalized gestures, let alone the more ad hoc iconic or beat gestures that are normally used in conversations. Indeed, existing dictionaries of conventionalized gestures also rarely indicate whether the movement is supposed to be repeated or not. However, indirect evidence does suggest that gestures may have similar formational preferences to those found in sign languages. For example, Kita et al. (1998) have demonstrated that two-handed gestures produced in discourse tended to be articulated with symmetrical movements and handshapes, just like sign languages (in sign languages, this tendency of balanced signs to be produced with identical or opposing movements, identical handshapes and identical locations has been proposed to be phonological in nature, referred to as the Symmetry Condition, see Battison, 1978; Napoli and Wu, 2003; Eccarius and Brentari, 2007). Though the authors ultimately conclude that the tendency for symmetry is cognitive rather than motoric in nature (cf. Eccarius and Brentari, 2007; Hwang et al., 2014), this does suggest that it is reasonable to expect gesture to exhibit phonetic properties common to sign languages. Future research should take a closer look at bimanual co-speech gesture.

What we suggest is that language emergence is subject to multiple pressures, and one of these pressures is biomechanics: languages will make use of motoric patterns that are easy to produce, and they are easy to produce probably because they have evolved/were selected for some other, nonlinguistic functions. One such easy motoric pattern is repeated alternating bimanual movements, which evolved originally for quadrupedal locomotion, but which are still active in arm movements due to the activation of CPG nerve-cell networks (see Introduction). This preference is just one of many biomechanically efficient movement patterns that require little central feedback control (e.g., see Stevens, 1989, Stevens, 2005; Stevens and Keyser, 2006; Gick et al., 2011; Gick, 2012; Gick and Stavness, 2013; Moisik and Gick, 2013, among others). Not all easy motoric patterns will be selected for, because not all of them will result in perceptual advantages, for example, or they may conflict with other motoric preferences, and so on. But what is selected for in articulation will be a subset of what is articulatorily advantageous. This tendency is modality-general, meaning that we expect both spoken and signed languages to select for such motorically advantageous patterns, among other pressures. The selection process for specific forms, therefore, is constrained both by the brain (computational costs) and by the body (articulatory costs). We hope that this paper will encourage more research into how evolutionary adaptations for movement in general can contribute to the linguistic structure of languages, both signed and spoken.

\section{DATA AVAILABILITY STATEMENT}

Publicly available datasets were analyzed in this study. This data can be found here: The datasets used are publicly available dictionaries of sign languages.

\section{AUTHOR CONTRIBUTIONS}

OT and BG conceived the presented idea as well as designed the study. OT did the background research on CPGs and sign languages, did data analysis and statistical calculations, and wrote the paper. GP coded the data, as well as provided signnaive judgements on iconicity of the analyzed signs.

\section{FUNDING}

This project was funded by NIH Grant DC-002717 to Haskins Laboratories. 


\section{REFERENCES}

Ballesteros, M. L. F., Buchthal, F., and Rosenfalck, P. (1965). The pattern of muscular activity during the arm swing of natural walking. Acta Physiol. Scand. 63 (3), 296-310. doi:10.1111/j.1748-1716.1965.tb04069.x

Battison, R. (1978). Lexical borrowing in American sign language silver spring. St Silver Spring, MD: Linstok Press.

Battison, R. (1974). Phonological deletion in American sign language. Sign Language Studies 1005 (1), 1-19. doi:10.1353/sls.1974.0005

Brennan, M., and Brien, D. (1992). Dictionary of British sign language/English. London, United Kingdom: Faber and Faber.

Brentari, D. (1998). A prosodic model of sign language phonology. Cambridge, MR: Mit Press.

Bruce, V., and Green, P. (1990a). Visual perception, physiology and ecology. Hillsdale, NJ: Erlbaum.

Bruce, V., and Green, P. (1990b). Visual perception, physiology and ecology. 2nd Edn. Hillsdale, NJ: Lawrence Erlbaum Associates.

Butler, P. J. (1991). Exercise in birds. J. Exp. Biol. 160 (1), 233-262.

Caselli, N. K., and Pyers, J. E. (2017). The road to language learning is not entirely iconic: iconicity, neighborhood density, and frequency facilitate acquisition of sign language. Psychol. Sci. 28 (7), 979-987. doi:10.1177/0956797617700498

Caselli, N. K., Sehyr, Z. S., Cohen-Goldberg, A. M., and Emmorey, K. (2017). ASLLEX: a lexical database of American Sign Language. Behav. Res. Methods 49 (2), 784-801. doi:10.3758/s13428-016-0742-0

Cheek, A., Cormier, K., Repp, A., and Meier, R. P. (2001). Prelinguistic gesture predicts mastery and error in the production of early signs. Language 77 , 292-323. doi:10.1353/lan.2001.0072

Chen Pichler, D., Dicus, D., Dudley, S., Taylor, S., and Watkins, M. (2016). Refining coding criteria for phonological accuracy of L2 signing. "Paper Presented at the 12th International Conference for Theoretical Issues on Sign Language Research. Melbourne, VIC. doi:10.1093/oxfordhb/9780190241414. 013.14

Chen Pichler, D. (2012). "Language acquisition," Handbook of linguistics and communication science. Sign Language (Berlin: De Gruyter Mouton), 647-686.

Costello, E. (1998). Random house webster's American sign language dictionary. New York City, NY: Random House Reference.

Crasborn, O. (2001). Phonetic implementation of phonological categories in Sign Language of Netherlands. Doctoral dissertation. Leiden, Netherlands: Universiteit.

Crasborn, O., and Sáfár, A. (2016). "An annotation scheme to investigate the form and function of hand dominance in the Corpus NGT." A matter of complexity. Berlin, Germany: Walter de Gruyter, 231-251. doi:10.1515/ 9781501503238-010

Dietz, V. (2002). Do human bipeds use quadrupedal coordination?. Trends Neurosci. 25 (9), 462-467. doi:10.1016/s0166-2236(02)02229-4

Dingemanse, M., Blasi, D. E., Lupyan, G., Christiansen, M. H., and Monaghan, P. (2015). Arbitrariness, iconicity, and systematicity in language. Trends Cognit. Sci. 19 (10), 603-615. doi:10.1016/j.tics.2015.07.013

Eccarius, P., and Brentari, D. (2007). Symmetry and dominance: a cross-linguistic study of signs and classifier constructions. Lingua 117 (7), 1169-1201. doi:10. 1016/j.lingua.2005.04.006

Emmorey, K. (2001). Language, cognition, and the brain: insights from sign language research. Hove, East Sussex, United Kingdom: Psychology Press.

Fagard, J. (1994). "Manual strategies and interlimb coordination during reaching, grasping, and manipulating throughout the first year of life," in Interlimb coordination: neural, dynamical, and cognitive constraints. Editors S. P. Swinnen, H. Heuer, J. Massion, and P. Casaer (San Diego, CA: Academic Press), 461-490.

Frishberg, N. (1975). Arbitrariness and iconicity: historical change in American Sign Language. Language, 696-719.

Gatesy, S. M., and Dial, K. P. (1996). Locomotor modules and the evolution of avian flight. Evolution 50 (1), 331-340. doi:10.1111/j.1558-5646.1996.tb04496.x

Gick, B., and Stavness, I. (2013). Modularizing speech. Front. Psychol. 4, 977. doi:10.3389/fpsyg.2013.00977

Gick, B. (2012). From quantal biomechanics to whole events: toward a multidimensional model for emergent. Can. Acoust. 40 (3), 24-25.
Gick, B., Stavness, I., Chiu, C., and Fels, S. (2011). Categorical variation in lip posture is determined by quantal biomechanical-articulatory relations. Can. Acoust. 39 (3), 178-179.

Gould, S. J., and Vrba, E. S. (1982). Exaptation-a missing term in the science of form. Paleobiology 8, 4-15. doi:10.1017/s0094837300004310

Grillner, S., and Wallén, P. (1985). Central pattern generators for locomotion, with special reference to vertebrates. Annu. Rev. Neurosci. 8 (1), 233-261. doi:10. 1146/annurev.ne.08.030185.001313

Grillner, S. (1985). Neurobiological bases of rhythmic motor acts in vertebrates. Science 228 (4696), 143-149. doi:10.1126/science.3975635

Grosvald, M., and Corina, D. P. (2012). "The production and perception of subphonemic vowel contrasts and the role of the listener in sound change," in The initiation of sound change: Perception, production, and social factors (Amsterdam, Netherlands: John Benjamins Publishing), 77.

Tang, G. (2007). Hong Kong sign language, Hong Kong, China: Chinese University Press.

Hickok, G., Kritchevsky, M., Bellugi, U., and Klima, E. S. (1996). The role of the left frontal operculum in sign language aphasia. Neurocase 2 (5), 373-380. doi:10. 1080/13554799608402412

Holzrichter, A. S., and Meier, R. P. (2000). Child-directed signing in American sign language. Hove, East Sussex, United Kingdom: Psychology Press, 25-40.

Hwang, S., Hollifield, D., Seegers, S., and Padden, C. A. (2014). Phonological constraints on two-handed productions in sign-naive gesturers. Minneapolis, MN: Meeting of the Linguistic Society of America.

Jacob, F. (1977). Evolution and tinkering. Science 196 (4295), 1161-1166. doi:10. $1126 /$ science. 860134

Johnston, T. (2001). Nouns and verbs in Australian sign language: an open and shut case? J. Deaf Stud. Deaf Educ. 6 (4), 235-257. doi:10.1093/deafed/6.4.235

Juncos, O., Caamaño, A., José Justo, M., López, E., Rosa Rivas, M., Teresa López, M., et al. (1997). Primeras palabras en la lengua de signos española (LSE). estructura formal, semántica y contextual. Rev. Logop. Foniatr. Audiol. 17 (3), 170-180. doi:10.1016/s0214-4603(97)75662-6

Kelso, J. A., Southard, D. L., and Goodman, D. (1979). On the nature of human interlimb coordination. Science 203 (4384), 1029-1031. doi:10.1126/science. 424729

Keyser, S. J., and Stevens, K. N. (2006). Enhancement and overlap in the speech chain. Language 82, 33-63. doi:10.1353/lan.2006.0051

Kita, S., and Essegbey, J. (2001). Pointing left in Ghana. Gest 1 (1), 73-95. doi:10. 1075/gest.1.1.06kit

Kita, S., van Gijn, I., and van der Hulst, H. (1998). "Movement phases in signs and co-speech gestures, and their transcription by human coders." in Proceeding of the Gesture and sign language in human-computer interaction, Bielefeld, Germany, September 1998, 23-35. doi:10.1007/bfb0052986

Klima, E. S., and Bellugi, U. (1979). The signs of language. Cambridge, MA: Harvard University Press.

Kuhtz-Buschbeck, J. P., and Jing, B. (2012). Activity of upper limb muscles during human walking. J. Electromyogr. Kinesiol. 22 (2), 199-206. doi:10.1016/j.jelekin. 2011.08.014

Ladefoged, P. (1984). A course in phonetics. San Diego, CA: Hartcourt, Brace Jovanovich.

Lakoff, G., and Johnson, M. (1980). Metaphor we live by. Chicago, IL: University of Chicago Press.

Lausberg, H., and Kita, S. (2003). The content of the message influences the hand choice in co-speech gestures and in gesturing without speaking. Brain Lang. 86 (1), 57-69. doi:10.1016/s0093-934x(02)00534-5

Lepic, R., Börstell, C., Belsitzman, G., and Sandler, W. (2016). Taking meaning in hand. SL\&L 19 (1), 37-81. doi:10.1075/sll.19.1.02lep

Lindblom, B. (1990). On the notion of "possible speech sound". J. Phonetics 18 (2), 135-152. doi:10.1016/s0095-4470(19)30398-5

Lindblom, B. (1998). "Systemic constraints and adaptive change in the formation of sound structure," in Approaches to the evolution of language: Social and cognitive bases (Cambridge, United Kingdom: Cambridge University Press), 242-264.

MacNeilage, P. F. (1998). The frame/content theory of evolution of speech production. Behav. Brain Sci. 21 (4), 499-546. doi:10.1017/s0140525x98001265

Meier, R. P., Cheek, A., and Moreland, C. J. (2002). "Iconic versus motoric determinants of the form of children's early signs," in BUCLD 26: 
proceedings of the 26th annual boston University Conference on language development, Boston, MA, November 2002, 393-405.

Meier, R. P., Mauk, C. E., Cheek, A., and Moreland, C. J. (2008). The form of children's early signs: iconic or motoric determinants?. Lang. Learn. Dev. 4 (1), 63-98. doi:10.1080/15475440701377618

Meier, R. P., Mauk, C., Mirus, G. R., and Conlin, K. E. (1998). "Motoric constraints on early sign acquisition," in Proceedings of the child language research forum (Stanford, CA: CSLI Press), 29, 63-72.

Meir, I., Sandler, W., Padden, C., and Aronoff, M. (2010). Emerging sign languages. Oxford handbook of deaf studies, language, and education 2, 267-280. doi:10. 1093/oxfordhb/9780195390032.013.0018

Meyns, P., Bruijn, S. M., and Duysens, J. (2013). The how and why of arm swing during human walking. Gait Posture 38 (4), 555-562. doi:10.1016/j.gaitpost. 2013.02.006

Moisik, S., and Gick, B. (2013). "June). The quantal larynx revisited," in Proceedings of meetings on acoustics ICA2013, Montreal, Canada, June, 2013. Acoustical Society of America, 19.

Morgan, G., Barrett-Jones, S., and Stoneham, H. (2007). The first signs of language: phonological development in British Sign Language. Appl. Psycholinguist. 28 (1), 3-22. doi:10.1017/s0142716407070014

Motamedi, Y., Little, H., Nielsen, A., and Sulik, J. (2019). The iconicity toolbox: empirical approaches to measuring iconicity. Lang. $\operatorname{cogn}$. 11 (2), 188-207. doi:10.1017/langcog.2019.14

Napoli, D. J., Sanders, N., and Wright, R. (2014). On the linguistic effects of articulatory ease, with a focus on sign languages. Language 90, 424-456. doi:10. 1353/lan.2014.0026

Napoli, D. J., and $\mathrm{Wu}$, J. (2003). Morpheme structure constraints on two-handed signs in American Sign Language. SL\&L 6 (2), 123-205. doi:10.1075/sll.6.2.03nap

Nespor, M., and Sandler, W. (1999). Prosody in Israeli sign language. Lang. Speech 42 (2-3), 143-176. doi:10.1177/00238309990420020201

Occhino, C., Anible, B., Wilkinson, E., and Morford, J. P. (2017). Iconicity is in the eye of the beholder. Gest 16 (1), 100-126. doi:10.1075/gest.16.1.04occ

Ormel, E., and Crasborn, O. (2012). Prosodic correlates of sentences in signed languages: a literature review and suggestions for new types of studies. Sign Lang. Stud. 12 (2), 279-315. doi:10.1353/sls.2011.0019

Östling, R., Börstell, C., and Courtaux, S. (2018). Visual iconicity across sign languages: large-scale automated video analysis of iconic articulators and locations. Front. Psychol. 9, 725. doi:10.3389/fpsyg.2018.00725

Ostrom, J. H. (1986). The cursorial origin of avian flight. Memoir. Calif. Acad. Sci. 8, 73-81.

Ostry, D. J., Cooke, J. D., and Munhall, K. G. (1987). Velocity curves of human arm and speech movements. Exp. Brain Res. 68 (1), 37-46. doi:10.1007/BF00255232

Padden, C. A., and Perlmutter, D. M. (1987). American Sign Language and the architecture of phonological theory. Nat. Lang. Ling. Theor. 5 (3), 335-375. doi:10.1007/bf00134553

Perniss, P., Lu, J. C., Morgan, G., and Vigliocco, G. (2018). Mapping language to the world: the role of iconicity in the sign language input. Dev. Sci. 21 (2), e12551. doi:10.1111/desc. 12551

Sanders, N., and Napoli, D. J. (2016). Reactive effort as a factor that shapes sign language lexicons. Language 92 (2), 275-297. doi:10.1353/lan.2016.0032

Sandler, W., and Lillo-Martin, D. (2006). Sign language and linguistic universals. Cambridge, United Kingdom: Cambridge University Press.

Siedlecki, T., Jr., and Bonvillian, J. D. (1993). Phonological deletion revisited: errors in young children's two-handed signs. Sign Lang. Stud. 1080 (1), 223-242. doi:10.1353/sls.1993.0000

Siple, P. (1978). Visual constraints for sign language communication. Sign Lang. Stud. 1019 (1), 95-110. doi:10.1353/sls.1978.0010
Stavness, I., Gick, B., Derrick, D., and Fels, S. (2012). Biomechanical modeling of English/r/variants. J. Acoust. Soc. Am. 131 (5), EL355-EL3600. doi:10.1121/1. 3695407

Stevens, K. N. (2005). "Features in speech perception and lexical access," in The handbook of speech perception (Hoboken, NJ: Wiley), 125-155.

Stevens, K. N. (1989). On the quantal nature of speech. J. Phonetics 17 (1-2), 3-45. doi:10.1016/s0095-4470(19)31520-7

Supalla, T., and Newport, E. (1978). "How many sits in a chair? The derivation of nouns and verbs in American Sign Language," in Understanding language through sign language research. Editor P. Siple (New York, NY: Academic Press), 91-132.

Taub, S. F. (2001). Language from the body: iconicity and metaphor in American sign language. Cambridge, United Kingdom: Cambridge University Press.

Thompson, R. L., Vinson, D. P., Woll, B., and Vigliocco, G. (2012). The road to language learning is iconic: evidence from British Sign Language. Psychol. Sci. 23 (12), 1443-1448. doi:10.1177/0956797612459763

Tkachman, O., Hall, K. C., Fuhrman, R., and Aonuki, Y. (2019). Visible amplitude: towards quantifying prominence in sign language. J. Phonetics 77, 100935. doi:10.1016/j.wocn.2019.100935

Tkachman, O., and Sandler, W. (2013). The noun-verb distinction in two young sign languages. Gest 13 (3), 253-286. doi:10.1075/gest.13.3.02tka

Tolar, T. D., Lederberg, A. R., Gokhale, S., and Tomasello, M. (2008). The development of the ability to recognize the meaning of iconic signs. J. Deaf Stud. Deaf Educ. 13 (2), 225-240. doi:10.1093/deafed/enm045

Tyrone, M. E., and Woll, B. (2008). Palilalia in sign language. Neurology 70 (2), 155-156. doi:10.1212/01.wnl.0000279378.09844.89

Van der Kooij, E., Crasborn, O., and Emmerik, W. (2001). Weak drop in sign language of The Netherlands," in Signed languages: Discoveries from international research (Washington, DC: Gallaudet University Press), 27-44.

van Emmerik, R. E., Wagenaar, R. C., and van Wegen, E. E. (1998). Interlimb coupling patterns in human locomotion: are we bipeds or quadrupeds?. Ann. N Y. Acad. Sci. 860 (1), 539-542. doi:10.1111/j.1749-6632.1998.tb09098.x

Vennes, L. (2018). Weak hand lowering and weak drop: the influence of sub-lexical iconicity on sign language phonology. Unpublished Masters Thesis. Nijmegen (Netherlands): Radboud University.

Wilbur, R. B. (2008). "Complex predicates involving events, time and aspect: is this why sign languages look so similar." in Theoretical issues in sign language research (Chicago, IL: University of Chicago Press), 217-250.

Wilbur, R. B., and Nolen, S. B. (1986). "Reading and writing." in Gallaudet Encyclopedia of Deaf People and Deafness (New York, NY: McGraw-Hill), 146-151.

Wittmann, H. (1991). Classification linguistique des langues signées non vocalement [Linguistic classification of non-oral sign languages]. Rev. Québécoise Linguistique Théor. Appl. 10 (1), 88.

Zehr, E. P., and Duysens, J. (2004). Regulation of arm and leg movement during human locomotion. Neuroscientist 10 (4), 347-361. doi:10.1177/1073858404264680

Conflict of Interest: The authors declare that the research was conducted in the absence of any commercial or financial relationships that could be construed as a potential conflict of interest.

Copyright $\odot 2021$ Tkachman, Purnomo and Gick. This is an open-access article distributed under the terms of the Creative Commons Attribution License (CC BY). The use, distribution or reproduction in other forums is permitted, provided the original author(s) and the copyright owner(s) are credited and that the original publication in this journal is cited, in accordance with accepted academic practice. No use, distribution or reproduction is permitted which does not comply with these terms. 